\title{
Networking at the Interface between Conceptual and Linguistic Metaphor in Comparative Literary Texts
}

\begin{abstract}
Recent advances in the cognitive linguistic approach to metaphor studies based on Conceptual Metaphor Theory (CMT) have contributed considerably to our knowledge of how figurative language is created in the mind. There appears to be a gap in knowledge, however, regarding the range of possible conceptual models represented in language itself. The creation of a linguistic metaphor may also depend on a large number of non-conventional features in addition to the types of more conventional trends highlighted by CMT. The field of comparative literature lends itself well to exploring these less conventional influences on the creation of figurative language. Consequently, the referential meanings found in literary mappings are frequently more diverse and open to interpretation. The present study will give a brief overview of some of the different features involved at the interface between conceptual and linguistic metaphors with regard to the works of three well-known twentieth-century authors. The hypothesis proposed here is that the meaning of a given literary metaphor can be networked to different referential mappings of the same conceptual metaphor. This is due to patterns originating in very personal forms of experience, ideals, and feelings portrayed through the characters of a novel.
\end{abstract}

Keywords: cognitive linguistics, comparative metaphor studies, conceptual networking, emotions, literary discourse

\section{Recent theories of metaphorization}

This paper investigates emotion metaphors from the perspective of both cognitive linguistics and comparative literary studies in relation to the works of three well-known European writers of the twentieth century: D. H. Lawrence, Hermann Hesse, and Simone de Beauvoir. The focus of this analysis will be on how all three writers have mapped metaphors of love onto the domain of death, but for very different reasons. Although a number of cognitive linguists have proposed models of love metaphors according to conventional aspects of modern society (Lakoff 1987; Lakoff and Johnson 1980; Kövecses 1988), this study suggests that literary works create very different types of non-conventional metaphors based on indi- 
vidual experiences and psychological states. In addition, a given conceptual metaphor may be construed according to types of conceptualization which diverge from standard emotion metaphors in everyday language. As a consequence, the major claim in this study is not only that linguistic metaphors are networked from conceptual metaphors (Trim 2007, 18-27), but that conceptual metaphors also produce different subgroups of conceptualization based on individual experience.

The emotion of love has been well documented in the seminal work of traditional cognitive metaphor theory, or CMT for short (Lakoff and Johnson 1980). A conventional metaphor for love would thus be LOVE IS A JOURNEY, as a parallel to the oft-cited LIFE IS A JOURNEY (Lakoff and Turner 1989, 9). Linguistic expressions linked to the JOURNEY metaphor would be: "our love is off the tracks" (i.e. going the wrong way) or "our love is on the rocks" (i.e. not progressing; Lakoff and Johnson 1980, 141). These tend to be generalized everyday expressions that have a universal tendency based on the JOURNEY metaphor. Be that as it may, even such expressions are not necessarily found in all cultures around the world, since some societies can have different attitudes towards love and may use other conceptual metaphors. In the Hmong language in Laos and Thailand, the JOURNEY metaphor is apparently replaced by a LIFE IS A STRING mapping (Kövecses 2005, 71).

At the turn of this century, certain cognitive linguists became more aware of the problems which such generalizations raised. As can be seen in the case of the JOURNEY metaphor, Kövecses weighed up the differences between universals and culture (2005). Later, he examined the role of context (Kövecses 2015), discussing the most immediate aspects of the physical, linguistic, intertextual, cultural, social, spatial, and temporal parameters of metaphor creation. In recent years, studies in conceptual metaphor involving the literary field suggest that a deeper understanding of metaphor has to go beyond basic everyday expressions (Fludernik 2011). One such example from the field of emotions is the idea of the inexpressibility of romantic love (Habermann 2011, 77-92). The claim here, with reference to some poems, is that many metaphors are based on the notions of silence, inscrutability, and ineffability. In John Donne's “The Extasie," first published in 1633, romantic love cannot be expressed in words:

And whil'st our soules negotiate there,

We like sepulchral statues lay;

All day, the same our postures were,

And we said nothing, all the day. (Donne 1912, 17-20)

The speaker and his love lie on a bank surrounded by flowers, but there is no verbal action. According to Habermann, the poem describes this union as a unio mystica in analogy to the union of the soul with God $(2011,79)$. 
By separating out different types of discourse such as everyday language, journalism, or literary works, it can be seen that varied types of cognitive processes can operate in metaphorization. Not only do diversified types of discourse come into play: it could be argued that language structures, such as morphosyntax, also influence the type of stylistic effects which can be produced from one language to another (Trim, in press). Hence the need not only for comparative literary studies on emotion metaphors, but also for literary studies in different languages, to fully understand the extent of the problem. However, the division between conceptual and linguistic metaphor represents an extremely useful tool for the analysis of metaphorization in literature.

\section{Comparative literature and the love/death theme}

In the light of traditional cognitive views on love metaphors, a LOVE IS DEATH mapping would be considered to be non-conventional. It does not appear in the detailed works on love metaphors in the standard works of cognitive linguistics, for example, the love metaphors proposed by Lakoff and Johnson (1980) or Kövecses (1988). However, a deeper analysis of this conceptual metaphor reveals that it has existed in European cultural history for a long time. Love and death are closely related in Ovid's story of Pyramus and Thisbe (Ovid 2008, 4.55-165), as well as in the legend of Tristan and Isolde from its twelfth-century origins to Wagner's opera. In Shakespeare's Anthony and Cleopatra, death is likened to a noble concept of true love. A bridegroom metaphor is used for the notion of being wedded in death:

But I will be

A bridegroom in my death, and run into't

As to a lover's bed. (Shakespeare 2001, 4.14.99-101)

It will be suggested in the analyses below that death is often symbolized as love in different concepts and images. No doubt, the long-term aspect of this cultural development has been linked to religious love, that is, the love of God and the idea of life after death. Despite the frequent application of the positive aspects of scenarios in which death is conceived of as love, metaphors that correlate love and death can also introduce extremely negative feelings. This appears to be the case with the three authors discussed in this study: Lawrence, Hesse, and Beauvoir. 


\subsection{Identical conceptual metaphors and differing referents}

The referents of identical mappings in conceptual metaphors can be substantially diverse, involving a large variety of linguistic metaphors. Lawrence, Hesse, and Beauvoir were more or less contemporaries. But despite working in the same historical period and, to a certain extent, the influence of comparable social and historical events, their personal experiences were quite different. Lawrence's metaphors of love were greatly influenced by the effects of World War I; many of Hesse's metaphors bear the hallmark of Freudian psychology; and Beauvoir's imagery stems from the existentialist philosophy current in French literature at the time. All three writers were in contact with Freudian psychology, but viewpoints tended to vary. Simone de Beauvoir, for example, rejected the Freudian approach to female sexuality, and felt that psychoanalysis placed too much emphasis on an individual's past and not enough on freedom of choice (Bieber 1979, 117). The result was that, apart from the different linguistic metaphors used, referents included in their mappings of love and death also varied considerably.

The mapping process in these brief case studies therefore incorporates three fundamental pivots: (a) an identical conceptual metaphor, LOVE IS DEATH; $(b)$ linguistic metaphors networked from this common conceptual metaphor; and (c) referents which determine the type of linguistic metaphor used. In order to exemplify this process, the background of each author and their use of emotion metaphors will be compared to see how the networking process takes shape.

\subsection{H. Lawrence and non-conventional love metaphors}

The novel by Lawrence chosen for this study is The Rainbow (1915), which narrates, in particular, the doomed love affair between the main protagonist, Ursula, and a British soldier of Polish descent, Anton Skrebensky. The novel portrays the lives of three generations of the Brangwen family in the East Midlands of England during a period of increasing industrialization. It is this feature of industrialization, together with the difficult period of World War I, which strikes a particularly pessimistic note in Lawrence's writings. He saw the industrial complex of pursuing war as "Western society's suicide" (Marnat 1966, 47-48) at the expense of the individual. Skrebensky is a soldier about to depart for the front, leaving Ursula behind. It could therefore be argued that the kissing and romantic love in various scenes of the novel actually reflect the horrors of the battlefield. The atmosphere of such scenarios is seen clearly in chapter 11, when, as an effect of Lawrence's metaphors, the romantic love scenes take on a very austere and harsh feeling: 
(1) He strove subtly, but with all his energy, to enclose her, to have her. And always she was burning and brilliant and hard as salt, and deadly. Yet obstinately, all his flesh burning and corroding, as if he were invaded by some consuming, scathing poison, still he persisted, thinking at last he might overcome her. Even, in his frenzy, he sought for her mouth with his mouth, though it was like putting his face into some awful death. (Lawrence 1915, 321; my emphasis)

(2) And she began to caress him to life again. For he was dead. And she intended that he should never know, never become aware of what had been. She would bring him back from the dead without leaving him one trace of fact to remember his annihilation by. (Lawrence 1915, 322-323; my emphasis)

In passage (1), Skrebensky feels he is kissing death and that the love relationship resembles scathing poison. In (2), he metaphorically dies and Ursula tries to bring him back to life. Using a cognitive linguistic analysis, the underlying conceptual metaphor therefore appears to be LOVE IS DEATH. It could also be argued that there are offshoots from this basic mapping. From Ursula's viewpoint, there are forces within the scenario which oppose this projection and perhaps portray an opposite LOVE IS LIFE mapping. Linguistic metaphorical expressions are networked from the opposing conflicts within the LIFE/DEATH conceptual metaphor: "scathing poison," "putting his face into some awful death" (i.e. a death-like mouth), "caress him to life again," "back from the dead," and "annihilation." The question then arises as to why metaphors related to death are equated to love. The answer perhaps lies in the mapping's referent regarding Lawrence's sentiments mentioned above: the destruction caused by the industrial complex of World War I. Lawrence has thereby innovated metaphors of a love relationship.

\subsection{Hermann Hesse's conflicts in love}

It could be claimed that Hesse's use of this conceptual metaphor springs more from his own psychological constitution than from an external influence as in the case of Lawrence. However, the psychological disorders he suffered from were probably also intensified by World War I during his childhood period. Indeed, Hesse had suicidal tendencies at different times of his life and had to seek psychiatric treatment from a follower of Carl Jung, namely Josef Lang. During the period of June to November 1916, he took a series of around sixty therapy sessions with Lang. This form of treatment apparently helped Hesse to further develop his literary career (Zeller 1963, 76).

The work chosen for this study of love metaphors is his famous novel Steppenwolf. His emotion metaphors reflect two types of human characteristics. The first is a reference to the high, spiritual nature of man which mirrors Hesse's own 
upbringing and education in "noble" environments such as the Church and classical concerts. The second is a sort of rebellion against this upbringing in the form of a low and animalistic nature. This can be seen in the symbolic aspect of the title: "the steppe wolf." The plot represents a complex psychological study, and the referents of Hesse's metaphors go deep into his own psyche. His metaphors appear to be intimately related to Freudian psychology. A characteristic dichotomy in this psychology entails those metaphors linked to a life drive and those linked to a death drive. The following passage (3) refers to the life drive by using images of stars and constellations, blooming flowers, and so on. The narrative behind the imagery concerns a casual love affair between one of the main protagonists, the fun-loving Maria, and Harry Haller: ${ }^{1}$

(3) For some moments, my heart stood still from the delight and sadness evoked by the rich picture gallery of my life and how full of distant eternal stars and constellations the poor steppe wolf's soul had been. In the infinite blueness, childhood and Mother appeared to gaze tenderly and blissfully over a distant and faded stretch of mountains. The choir of my circle of friends rang out, beginning with the incredible Hermann, Hermine's soul brother. Fragrant and unearthly, like moist, blooming water flowers, the images of many women I had loved, admired, and praised were swimming before me, few of whom I had had within my reach or tried to possess. (Hesse 1927, 122; my emphasis)

The death drive is represented by a meeting with another woman in the novel, Hermine, who occasionally works as a prostitute. The encounter is a form of seduction in which Haller realizes what he should be doing more himself: learning to laugh and live life to the full. He should actually become the steppe wolf. However, the consequences of this seduction draw Haller into the darker sides of existence, including the murder of his lover later on in the complex and metaphorical "magical theatre" of his mind. The "theatre" includes a long corridor with mirrors facing doors that represent different periods of Haller's life. As he is introduced to taking drugs by Hermine, the hallucinating effects tend to represent the state of his mind rather than the reality of the situation. This "journey through hell," which is represented by the magical theatre, is the point at which Haller attempts to come to terms with his life. According to Zeller, the mirrors metaphorically open up pathways which lead to explanations about his self (1963, 101).

In this vein, passage (4) creates linguistic metaphors of an abyss, depths, and sacrificing life from the LOVE IS DEATH conceptual metaphor:

1 Translations in this article are my own. 
(4) And yet that was only the outer surface: within, everything was full of significance, tension, and destiny. While I was lovingly and tenderly occupied with the small, sweet, and moving sides to love, and seemed to be swimming in the warm waters of happiness, I felt deep down that my fate was striving forward head over heels, beating and kicking like a timid steed, towards an abyss, a plunge into the depths, full of fear, longing, and sacrificing my life. (Hesse 1927, 137; my emphasis)

To briefly sum up the creation of love metaphors used by Hesse, it could be argued they fall into two main categories which follow Freudian theories of Eros and Thanatos. These can be applied to the changing moods of the protagonist, Haller, in his encounters with Maria. In his essay Beyond the Pleasure Principle, Freud suggests that life instincts are responsible for Eros and are based on survival, pleasure, and reproduction (Freud [1920] 1990). The ancient Greek god of love, Eros, symbolizes this life drive. On the other hand, there also appears to be an unconscious wish to die, which is brought out by the fact that people who have witnessed traumatic events, such as war, are often drawn towards them again in dreams. This compulsion is a death drive symbolized by the ancient Greek god of death, Thanatos, although it was actually Stekel (1911) who introduced the term "Thanatos." The death drive thus stands in contradiction to the desire to survive, have pleasure, and reproduce.

Whether or not Hesse himself experienced this form of dualism is difficult to assess, but his association with Freudian psychology at the time suggests that the predominant psychological thought of the period played a part in the representation of Haller's changing moods. From a language point of view, the life drive creates positive, and more conventional, linguistic metaphors with referents relating to the "nobler" side of his life. Cognitively speaking, the death drive tends to lend itself to more non-conventional metaphors that often incorporate the negative aspects of downward orientation such as an abyss. The types of referents used arise from the protagonist's desire to break away from the past and become the steppe wolf. The LOVE IS DEATH conceptual metaphor takes on very different types of referential meaning in the third case of this comparative study: Simone de Beauvoir. Her writings reflect more precisely philosophical developments in France at that time.

\subsection{Simone de Beauvoir's conceptualization of a love triangle}

In relation to the point made above about authors' lives, the three case studies in this analysis of emotion metaphors raise the question not only of the extent to which they are a reflection of the authors' own experiences in love, but also of how far they are reflections of different historical concepts and discourses of love. 
Although authors' biographies often appear to be similar to ideas and feelings put forward in their works, it is not always possible to verify the balance between personal experience and cultural thought of the time. Beauvoir's first novel, L'Invitée (1943), is a case in point. The metaphors used in Beauvoir's novel are a reflection of her interest in existentialist philosophy, a predominant school of thought at the time she wrote the book, which claims that we are responsible for our acts and that our existence is dependent on these actions. In support of this theory, certain critics claim that self-consciousness of the partners in a love relationship is a major aspect of existentialism (Lukavská 1977, 52-65).

The second main point about Beauvoir's view of love relationships was that both love triangles and bisexual partnerships were not only acceptable but desirable - a view which was revolutionary in the 1940s. However, in the case of Beauvoir's novel, the love triangle goes wrong for different reasons, so she employs various metaphors related to the negative conceptualization represented by the LOVE IS DEATH mapping.

Briefly, the plot revolves around the protagonist, Françoise, who has an open relationship with her partner, Pierre. A female friend, Xavière, introduced by Pierre, enters and forms a love triangle. A point which would need further clarification is how far Françoise, who is the narrator of the story, is really Beauvoir, Pierre is really Jean-Paul Sartre, Beauvoir's long-term partner in real life, and Xavière represents a bisexual partner that Beauvoir had during her early teaching career. However, the idealistic love triangle that Françoise wishes to create - as she says, "a united couple is already a marvellous thing but it is so much more beautiful when three people love each other" (Beauvoir 1943, 263) - soon runs into difficulties. As Lukavská states, the starting point in the decline of the relationship concerns Pierre's desperate attempt to gain the love of Xavière, a scenario which is complicated by the fact that the latter also falls in love with Gerbert, an actor in the theatre run by Pierre (Lukavská 1977, 51). During the following events, Françoise attempts to make amends with Xavière, but to no avail. At a certain point in the narrative, it becomes clear to Françoise that she will have to eliminate her rival, Xavière.

Two types of LOVE IS DEATH conceptual metaphors are used to portray the love relationships between Françoise and Pierre on the one hand, and Françoise and Xavière on the other. Françoise feels that the strength of love between her and Pierre is dying out, and she uses typical metaphors such as "bleached sepulchres" and "mummies" to symbolize the death of their relationship (Beauvoir 1943, 5, 6). When she refers to Xavière, she feels her role in the love triangle has an insidious and evil influence on the relationship between Françoise and Pierre. The metaphors used are "funeral shades," in reference to the lighting in Xavière's room, while "poisoned atmosphere" and "sticky smell" refer to the increasing feeling of 
jealousy $(7,8)$. The outcome of this relationship is that Françoise decides to kill Xavière at the end of the novel so that the atmosphere of death actually becomes reality:

(5) You always want your feelings to be the same, you need them close to you, well organized, unchanging, and even if nothing is left inside, you couldn't care less. They are like the Gospel's bleached sepulchres; they shine on the outside, they are solid, faithful, now and again you can even polish them up again with beautiful words. (Beauvoir 1943, 199; my emphasis)

(6) It's a serious matter, I'm sure I'm telling the truth; your feelings are unshakeable, they can survive for centuries because they are mummies. (Beauvoir 1943, 200; my emphasis)

(7) Over there, in the funeral shades of her room, Xavière was sitting, wrapped in her brown dressing-gown, looking gloomy and evil, Pierre's sorrowful love humbly stroking her feet. Françoise wandered around in the streets, rejected and putting up with the old remains of her worn-out affection. (Beauvoir 1943, 490; my emphasis)

(8) She took off her coat. She had to speak. But how? She could not mention Gerbert's secrets, and yet she could not live in this poisoned atmosphere. Between the smooth, blue panes and in the sticky smell of sun-tan lotion, Pierre's aggrieved feelings and Françoise's low jealousy undoubtedly existed. They had to be destroyed. Only Xavière could destroy them. (Beauvoir 1943, 491; my emphasis)

These innovative metaphors of love sum up two relationships in the trio which are leading to destruction and annihilation: on the one hand, the love for Pierre, whose symbols of people long-since deceased represent a relationship on the road to destruction and, on the other hand, the relationship to Xavière, in which the atmosphere of funerals and poison lead to the latter's annihilation.

At this point, we are able to determine the ways in which the three case studies network linguistic metaphors from the underlying conceptual mapping according to the writers' standpoints. This latter aspect may be conditioned largely by the writer's own philosophical views, an argument which appears to be supported by Simone de Beauvoir's work.

\section{Comparative networking in the LOVE IS DEATH metaphor}

The results of this analysis first suggest that a cognitive approach can reveal very different emotion metaphors compared to the everyday examples proposed above in standard CMT. First, the conceptual metaphor LOVE IS DEATH is unusual since 
this type of mapping does not fit into conventional partnerships: the love felt for someone is not usually conceptualized in terms of death. The second point is that specific linguistic metaphors, also unusual for love relationships, are networked from the underlying conceptual metaphor. These depend on differing attitudes to death in relation to reality as they are depicted differently in the three novels. In the case of Lawrence, the emotion metaphors suggest the environment of the love affair is leading to the death of Skrebensky, "putting his face into some awful death.” The scene anticipates and symbolizes Skrebensky's imminent departure to the front during World War I, one of the main events that haunted Lawrence at that time.

Different subgroups of networking may also arise from the underlying conceptual metaphor. In the case of Hesse, there appear to be two main subgroups: the life and death drives in love relationships. The first generates linguistic metaphors such as stars, constellations, and water flowers; the second may reflect Hesse's own suicidal tendencies and is expressed in the killing of Hermine, who incites her lover to kill her.

From a Freudian point of view, the killing of Xavière at the end of Beauvoir's novel could also represent a death drive. However, Beauvoir would argue that this scenario is directly in line with existentialist philosophy: each individual is responsible for his or her own acts. She uses the imagery of funeral shades and a poisoned atmosphere to represent the features of death.

This point leads to the types of linguistic metaphors used. Some figurative terms are innovative: annihilation, bleached sepulchres, mummies, funeral shades, and so on. Among them are concepts such as poison, which are used by more than one character. However, in each case the semantic referent is different. Each character has his or her own history, and, particularly in literary discourse, this may create extremely innovative metaphors that are not conventional in everyday terms.

The three pivots of metaphorization - the underlying conceptual metaphor, the ensuing linguistic metaphors, and the referents of each individual author could, in addition, lead to a secondary-level conceptualization process. This process could be visualized as a triangular network. In the case of the poison image, the underlying conceptual metaphor of LOVE IS DEATH produces a secondary-level death image focused on features such as the partner, the actual love affair, and so on. Point 1 in the network of the triangle would be the source domain, poison. Point 2 would be the target domain, love. Point 3 would be the referent, for example Xavière in Beauvoir's novel. The reasons behind the referent would be Xavière's problematic role in the love affair. The use of the same image by Lawrence and Beauvoir, namely poison, but with varying referents, originates from the authors' different frames of mind. In the case of Lawrence, its use stems from 
the rejection of war. If we apply existentialist theory here, it could be argued that the image of poison in Beauvoir's case is related to this theory: self-consciousness may seek to destroy another when it feels its interests are violated in some way or other and that it may therefore seek the death of others.

\section{Conclusions}

It may be concluded that the cognitive approach continues to be extremely useful in metaphor analysis. Ongoing research in this field appears, however, to require new studies of very innovative metaphors which are not necessarily aligned to everyday language or universal trends. It can be seen in the case studies of this analysis that the origins and semantic referents of conceptual metaphors may be extremely diverse. Although there are some similar metaphors based on the LOVE IS DEATH mapping, they often refer to very different types of experience, ideals, and feelings in their attitudes towards love. On the basis of a common underlying conceptual metaphor, linguistic metaphors are networked to a wide variety of innovatory figurative expressions. The global interpretation of metaphor usage is therefore fundamental to our understanding of how metaphors are created generally. On the basis of these kinds of comparative studies, we are able to see that the origins of metaphors, and particularly those linked to the emotions, are not always so cut and dried. It is hoped that this form of comparative study may contribute to our knowledge of how the individual creation of emotion metaphors can diversify the process involved.

\section{Works cited}

Beauvoir, Simone de. L'Invitée. Paris: Éditions Gallimard, 1943.

Bieber, Konrad. Simone de Beauvoir. Boston: Twayne, 1979.

Donne, John. “The Extasie.” 1633. The Poems of John Donne. Ed. Herbert J. C. Grierson. Vol. 1. Oxford: Clarendon Press, 1912. 51-53.

Fludernik, Monika, ed. Beyond Cognitive Metaphor Theory: Perspectives on Literary Metaphor. New York: Routledge, 2011.

Freud, Sigmund. Beyond the Pleasure Principle. 1920. Ed. James Strachey. Norton: Norton Library, 1990.

Habermann, Ina. "Reaching Beyond Silence: Metaphors of Ineffability in English Poetry Donne, Wordsworth, Keats, Elliot." Beyond Cognitive Metaphor Theory: Perspectives on Literary Metaphor. Ed. Monika Fludernik. New York: Routledge, 2011. 77-93.

Hesse, Hermann. Steppenwolf. Berlin: Fischer, 1927.

Kövecses, Zoltán. The Language of Love. Lewisburg: Bucknell University Press, 1988. 
Kövecses, Zoltán. Metaphor in Culture: Universality and Variation. Cambridge: Cambridge University Press, 2005.

Kövecses, Zoltán. Where Metaphors Come From: Reconsidering Context in Metaphor. Oxford: Oxford University Press, 2015.

Lakoff, George. Women, Fire and Dangerous Things. Chicago: University of Chicago Press, 1987.

Lakoff, George, and Mark Johnson. Metaphors We Live By. Chicago: University of Chicago Press, 1980.

Lakoff, George, and Mark Turner. More than Cool Reason: A Field Guide to Poetic Metaphor. Chicago: University of Chicago Press, 1989.

Lawrence, David Herbert. The Rainbow. London: Methuen, 1915.

Lukavská, Eva. “L'Invitée de Simone de Beauvoir.” Études romanes de Brno. Vol. 9. Brno: University of Masaryk Press, 1977. 52-64.

Marnat, Marcel. D. H. Lawrence. Paris: Editions Universitaires, 1966.

Ovid. Metamorphoses. Trans. A. D. Melville. Oxford: Oxford University Press, 2008.

Shakespeare, William. Antony and Cleopatra. Ed. Ania Loomba. New York: Norton, 2011.

Stekel, Wilhelm. Die Sprache des Traumes: Eine Darstellung der Symbolik und Deutung des Traumes in ihren Beziehungen zur kranken und gesunden Seele. Wiesbaden: Wiesbaden Verlag, 1911.

Trim, Richard. Metaphor Networks: The Comparative Evolution of Figurative Language. London: Palgrave Macmillan, 2007.

Trim, Richard. "Le rôle de la morphologie dans la création de la métaphore cognitive, abordé du point de vue de la traduction." Proceedings of the First World Congress on Translation Studies. Eds. Marc de Launay and Florence Lautel-Ribstein. Paris: Éditions Classiques Garnier. In press.

Zeller, Bernard. Herman Hesse. Hamburg: Rowohlt, 1963.

Richard Trim graduated in Modern Languages in the UK and went on to specialize in linguistics with a PhD from the University of London. He has lectured in linguistics at a number of universities around Europe and has published widely in the field of metaphor studies. He is currently professor in Linguistics at the University of Toulon, France. His main research areas include metaphor studies associated with cognitive linguistics, historical and contrastive linguistics, comparative literary and political discourse, as well as translation studies. 